\title{
Vias-criativas horizontais com turmas de ensino-médio Modos horizontales creativos con clases de escuela Secundaria
}

\author{
Horizontal creative ways with high school classes
}

\author{
Raimundo Kleberson de Oliveira Benicio \\ Artista múltiplo. Universidade Federal da Bahia, Programa de Pós-graduação em Artes Cênicas. \\ Bolsista. UFBA/PPGAC-FAPESB \\ kleberbeniciop@gmail.com
}

Rita Emanuela Cidade Sousa

Artista-professora

ritacidade16@gmail.com

RESUMO

A experiência compartilhada se refere a um percurso de ensino-aprendizagem no programa de Residência Universitária: subprojeto de Teatro da Universidade Regional do Cariri (URCA), realizado na EEFM Teodorico Teles de Quental na cidade do Crato/ $\mathrm{CE}$, cujo acompanhamento se deu por uma pesquisadora-docente formada na área de Licenciatura em Teatro, o que de certo modo, potencializou as provocações desta experiência. Com isso, foram buscadas estratégias como o uso do WhatsApp e outras redes sociais para o desenvolvimento das aulas com duas turmas de Segundos anos do Ensino Médio.

Palavras chave: Residência Pedagógica, Teatro, Pedagogia Teatral

\section{RESUMEN}

La experiencia compartida se refiere a una ruta de enseñanza-aprendizaje en el programa de Residencia Universitaria: subproyecto de teatro de la Universidad Regional de Cariri (URCA), realizado en EEFM Teodorico Teles de Quental en la ciudad de Crato / CE, que fue monitoreado por un investigador-maestro capacitado en el área de Licenciatura en Teatro, que, de alguna manera, aumentó las provocaciones de esta experiencia. Con esto, se buscaron estrategias como el uso de WhatsApp y otras redes sociales para el desarrollo de clases con dos clases de los años de la secundaria.

Palabras clave: Residencia Pedagógica, Teatro, Pedagogía Teatral

\section{ABSTRACT}

The shared experience refers to a teaching-learning path in the University Residency program: Theater subproject of the Universidade Regional do Cariri (URCA), held at EEFM Teodorico Teles de Quental in the city of Crato/ CE, which was monitored by a researcher-teacher trained in the area of Degree in Theater, which in a way, enhanced the provocations of this experience. With this, strategies were sought such as the use of WhatsApp and other social networks for the development of classes with two groups of Second High School years. .

Keywords: Pedagogical Residence, Theater, Theater Pedagogy 


\section{Introdução/Contexto Em Que Se Insere}

O projeto Residência pedagógica é uma ação do Programa de Aperfeiçoamento de Pessoal de Nível Superior (CAPES), cuja perspectiva permite um contato do licenciando com as escolas por um período maior de tempo, já que os Estágios Supervisionados muitas vezes, devido a seu curto prazo não possibilitam um aperfeiçoamento das práticas didáticas-pedagógicas dos projetos em acordo com o componente curricular. Lançado em 2018, o projeto caminha em uma fase prévia de ações educativas e apresenta diversas potencialidades quanto a sua relevância de desenvolvimento, porém, alguns aspectos também apresentam algumas problemáticas que são tensionadas e evidenciadas a partir de quem participou/acompanhou este programa recente.

A iniciativa do projeto evidencia uma tríade entre Universidade, Escolas e Secretaria de Educação. Além de propor uma carga horária que ultrapassa 400 horas exigidas pelo programa, o período dividido em sua dimensão abarca blocos estes como: imersão (período em que as e os residentes visitam a escola com o intuito de conhecer a sua infraestrutura, as docentes, as e os alunos), diagnóstico (com as observações geradas na imersão, as e os residentes detectam as possíveis precariedades que podem ser percebidas), planejamentos (período em que são lançadas as primeiras reflexões sobre os blocos anteriores e proporcionar metodologias antes de adentrar ao estágio prático), encontros semanais (reuniões com o intuito de reunir e discutir as etapas de cada bloco, bem como leituras e aprofundamentos preparatórios), regência (período em que de fato as e os residentes assumem a aula), reflexão das atividades (realização de relatórios parciais sobre a metodologia posta em prática), elaboração avaliativa (período em que se há a reflexão da prática e das discursões nos encontros).

\section{Recorte Subprojeto Teatro E Algumas Questões Sobre O Ir Ao Encontro Com A Turma E O Interesse Pelo Encontro}

Desta forma, me referirei ao compartilhamento enquanto residente do subprojeto teatro da Universidade Regional do cariri, realizada no período de 2018-2019, na escola Teodorico Telles de Quental, Crato/CE, com acompanhamento da preceptora e artista Rita Cidade.
As percepções aqui expostas foram refletidas durante 0 percurso que permaneci na regência com duas turmas de Segundos anos do Ensino Médio. A proposta metodológica surgiu de anotações com a vivência durante o período de imersão em que as/os residentes vivenciaram. O qual teve o intuito de conhecer a estruturação da escola, suas organizações administrativas e pedagógicas.

O projeto que desenvolvi se intitulou "ENTRE: Formas Animadas e Virtualidade" que teve como objetivo o uso de redes sociais como ferramenta potencializadora para o processo de ensino-aprendizagem com os/as estudantes, com recortes para provocações em que utilizássemos as formas animadas como propostas avaliativas, o objetivo surgiu de inquietações a partir da disciplina de Psicologia da Educação dentro da componente curricular do curso de Licenciatura em Teatro da URCA, contexto esse em que também adentrei no programa da Residência Pedagógica: subprojeto Teatro. Tal inquietação também esteve influenciada com a questão - o que poderia causar motivação nas aulas se estamos cada vez mais imersos na virtualidade e em redes sociais? Como podemos tirar proveitos destas plataformas como suporte para tratar de temas ligados a linguagens artísticas? Como identificar em sala de aula, em diversas turmas, ou que propostas poderia amenizar o estado de desinteresse de algumas/alguns?

A questão da motivação é uma das mais explícitas no cotidiano tanto universitário como escolar, a qual pode ser pretexto para a não-realização das participações na aula e provocações geradas durante os encontros. O pesquisador Abraham Maslow aponta para alguns dos fatores que podem estar associados a desmotivação participativa nas aulas, sendo elas: necessidades fisiológicas - ligadas ao sono, alimentação, casa, rotina. Necessidades de segurança-empregos estáveis, instabilidade, confiança nos outros. Necessidades sociais - amizades, relacionamentos, sentimentos, amor, busca pela reciprocidade. (PILETTI; ROSSATO, apud MASLOW, 2010).

O interesse pela matéria ou tema pode sofrer uma dualidade quanto a seu significado, devido a multiplicidade de interesses de cada indivíduo atingir, a maioria pode ser uma abordagem difícil, pois cada pessoa enquanto universo particular demonstra desejos diferenciados e múltiplos. Indagamos se é o assunto da aula que pode contribuir para 
o desinteresse ou é a forma política e rígida da estruturação da escola que prejudicam o processo de participação. A provocação permanece em aberto, em razão de levar em consideração o contexto em que a e o docente se encontra.

Quando nos concentramos no cumprimento das obrigatoriedades perdemos e atribuímos muitas vezes menos valor eficaz sobre o assunto. Quando não faz sentido para as/os estudantes, uma barreira parece ser evidente e detectada por elas e eles mesmo. O fator de interesse quando não alinhado a uma percepção da turma pode ser um contribuidor para a desmotivação, com isso, quando não há um fator de interesse com o tema/assunto/aula, o sentido da motivação pode ser reduzido.

As/os estudantes podem a exemplo, buscar outras necessidades pessoais de motivações, em razão de seus próprios desejos como: Necessidade de estima autoconfiança, autorrealização para permanecer nas redes sócias, ou ler conteúdos aleatórios, ou realizar as atividades de casa da aula anterior, dentre outras. Diante disso, sua autonomia se direciona para a realização de seus próprios desejos momentâneos. As propostas de despertar o pensamento crítico parecem hoje não contemplar o interesse de muitos contextos educacionais, em virtude de haver um estado de desmotivação geral, tanto das/dos próprias discentes como docentes.

Wallon (PILETTI; ROSSATO, 2010) traz uma abordagem interessante ao considerar a afetividade como uma propulsora que potencializa e provoca uma interação maior para o ensino-aprendizagem, com isso, o sentido do interesse sugere uma aproximação geral com a aula tanto para quem realiza como para quem expecta.

A ideia dos reforçadores difundidas segundo o pesquisador Skinner - Negativo e Positivo trazem provocações acerca dos incentivos de relacionamento estabelecidos durante o percurso dos encontros, seja elas semestrais, bimestrais ou anuais. Os Reforçadores Negativos estão associados à punição3, ou seja, quando uma/um aluna não consegue em seus processos de aprendizagem avançar em determinados conteúdos, ou é repreendida, sua capacidade de estímulos pode ser diminuída, ocorrendo uma fuga do conteúdo, dos estímulos ou dos interesses pelo tema.
Reforçadores Positivos estão associados ao elogio, quando a/o aluna se sente recompensada, poderá se ter um aumento na probabilidade de continuidade e dedicação em outras circunstância e repetição de suas ações. Em alguns casos, quando esses reforçamentos positivos deixam de ser com frequência, isso pode possibilitar na também queda de estímulos de interesse pelo tema ou pela aula. (PILETTI; ROSSATO, 2010).

Não podemos cair na generalização de associar tais preposições ao direcionamento de competitividade. Estarmos conscientes dos momentos em que esses reforçadores podem ser utilizados traz uma grande potência na construção de ética e grupalidade, a qual podemos tentar driblar e concomitantemente, propor o exercício de contextualização e cruzamento com o conteúdo programático das atividades didáticas do livro, respeitando os limites, o contexto e autonomia da turma.

\section{Métodos A Partir Do Olhar}

Com as observações durante o período de imersão na residência universitária e de percepções com as leituras nos encontros, surgiu a seguinte questão: $E$ se criarmos um grupo virtualmente, onde serão postadas pesquisas individuais sobre os assuntos trabalhado na aula?

Desta forma foram propostos três modos de realização de atividades para compor parte da avaliação do primeiro bimestre de 2019. Toda turma iniciou com 10 pontos, e tiveram o objetivo de mantê-los até a nota da primeira avaliação. Algumas regras foram estabelecidas como: não poderiam postar o mesmo material, o prazo máximo para cada postagem foi de 7 dias, inferido estas regras, 2 pontos eram diminuídos do total ganho.

\section{Contato}

Levando em consideração algumas frentes ampliadas e conscientes e de acordo com o conteúdo programado do livro didático Percursos da arte: volume único: ensino médio: arte (2010), como o "modernismo no Brasil" ou "Arte contemporânea", meus primeiros contatos com as duas turmas foram de forma perfomativa, onde desenvolvi uma ação programada que consistiu em entrar na sala, com óculos e vestimentas de cor preta ao som de uma música 
de suspense. Tal proposta teve a intensão de causar um primeiro estranhamento e proximidade com a turma que se sentiu convidada a participar caso houvesse vontade.

Com a instauração da atmosfera gerada com a ação performativa, foi possível perceber a atenção de todas e todos através dos próprios comentários durante o acontecimento. Em seguida, ao final desta ação, foi aberto um espaço para lançar algumas questões como: 0 que poderia ser considerado moderno? A qual gerou algumas respostas como - "romper com o convencional, algo atual", dentre outras. Devido ao tempo curto, as propostas das vias foram explicadas no nosso segundo encontro que era uma vez por semana, destaco a seguir:

\section{1a: Via de Pesquisas Exploratórias:}

Consistiu em incentivar pesquisas relacionadas aos temas tratados pelo livro didático, em consonância com o projeto da residência, essas através de imagens, textos, vídeos, áudios, dentre outros. Essa via objetiva-se na tentativa de construção de grupalidade e autonomia frente aos temas tratados e escolhidos de forma horizontal por cada pessoa da turma. Foi desenvolvida da seguinte forma - criado um grupo no WhatsApp para as postagens de suas pesquisas pessoais (imagens, vídeos, textos, dentre outras) no intuito de criar um "banco de dados" onde elas/eles puderam ter acesso a qualquer momento.

\section{2a: Via Cena Perfomática:}

Nesta via cada pessoa da turma poderia escolher temas do livro didático como: as vanguardas Europeias: Cubismo, Futurismo, Suprematismo, Dadaísmo, dentre outras e elaborassem uma cena individual ou grupo de no máximo $10 \mathrm{~min}$, sobre.

\section{3a: Via Escrita Poética:}

As pessoas que escolherem esta, deveriam realizar um pequeno texto poético de forma livre, sobre qualquer assunto tratado durante o percurso das aulas de Arte até o dia 22 abril 2019 (semana de avaliação AV1).

A proposta que mais escolheram foi a primeira e a terceira.
Meu projeto desenvolvido na residência pedagógica, ultrapassou o contato presencial e está diretamente relacionado com a virtualidade sendo uma parte proposta como compartilhamento no grupo do WhatsApp que serviu como continuidade das provocações geradas nas aulas, disso resultou em diversas imagens, vídeos, e textos, dentre outras, que serviram de apoio para propor uma contextualização nas aulas de arte, diante disso, minha regência de antemão, aconteceu tanto presencialmente, ao-vivo, como virtualmente levando em consideração e acreditando que a virtualidade pode ser espaço de redimensionamento como ferramenta construtora de pesquisas e grupalidade entre professora e alunas e alunos.

\section{A Voz Das Alunas/Alunos}

Com os depoimentos recolhidos durante uma avaliação proposta ao final do primeiro período: houve nos escritos uma boa aceitação quanto à pertinência com a via pesquisa exploratória, escolhida por quase todas e todos. Relatando a importância de ter contato com outras pesquisas e outras fontes divergentes uns das outras/outros. Destaco alguns destes escritos a seguir:

- Consegui compreender um pouco melhor, o que é a Arte e como ela acontece.

- Nos ajudou a explorar novos campos da Arte que eu não tinha intimidade, ajudando a ampliar nossos conhecimentos em relação ao mundo. Com auxílio da pesquisa exploratória nós podemos fugir um pouco da "pressão" escolar e conseguimos construir uma intimidade com o professor e novos conteúdos, assim, podendo evoluir nossos conhecimentos sobre o mundo.

- A pesquisa exploratória foi importante para entender melhor sobre os temas propostos, como o Modernismo no Brasil.

- Achei muito importante essas duas metodologias de pesquisa pois aprendi coisas que eu nunca vi, esse tipo de pesquisa me ajudou muito pois sei que vou precisar no futuro.

- Achei um método diferente e didático em comparação as demais matérias que insistem na mesmice de provas, 
de trabalhos. Obrigado por ter nos proporcionado esse momento, nos acompanhado com paciência e compreensão.

- Foi interessante por conta que foi tudo por internet, mostra que podemos usá-la como experiência.

- Aprender mais um pouco sobre determinado assunto, sobre fatos que marcaram e que ainda hoje marcam. Um dos pontos positivos foi que cada aluna/aluno, teve um determinado tempo para ampliar e enriquecer cada pesquisa.

- Foi algo diferente para eu fazer esse tipo de trabalho usando uma rede social, pois foi possível aprender com uma ferramenta que é usada diariamente, ajudou a adquirir conhecimentos diversos. Foi uma experiência bacana.

- Pude perceber que há diversos assuntos, me despertou mais interesse sobre o teatro, algo que eu não tinha antes.

- As/os alunas/alunos se dedicaram realmente a um trabalho, pesquisaram a fundo, aprenderam mais, foi uma pesquisa bem interessante, fui capaz de compreender muito.

- Além de adquirirem experiência, adquiriram aprendizagem, aprendemos a interpretar uma imagem, a dividir um mesmo ambiente com as colegas, ouvindo novas opiniões e novos conceitos.

- Sim, pois com a pesquisa vi vários vídeos e observei fatos interessantes, interessante a pesquisa é muito abrangente.

- Conheci várias formas de expressar a Arte, como por exemplo, o teatro de animação.

- Foi uma ideia diferente que rompeu com o padrão das aulas.

- Os trabalhos realizados nesse primeiro bimestre nos permitiram explorar e colocar em prática nossos conhecimentos de maneira simples, praticando, explorando e expressando.

- Achei a forma de descobrir coisas muito interessantes a partir de vídeos e fotos não só pesquisados por mim, mas também pelas minhas/meus colegas, despertando muitas vezes curiosidade para pesquisar seus assuntos.

- Teve importância sim, porque vamos entrando na internet, pesquisamos sobre o assunto, lendo, descobrindo mais.

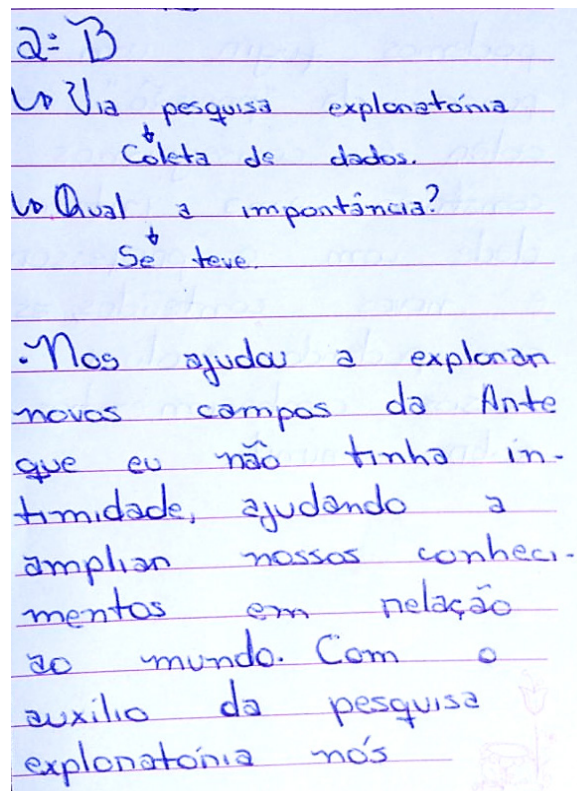

Figura 1. Escritas avaliativas sobre a via Pesquisa Exploratória

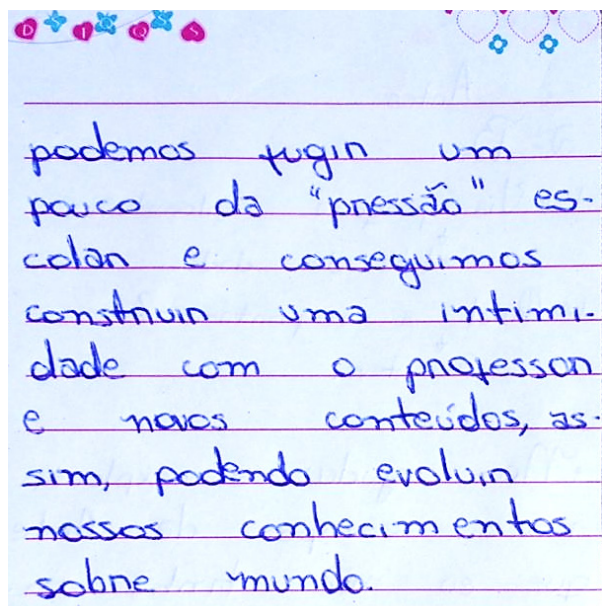

Figura 2. Escritas avaliativas sobre a via Pesquisa Exploratória

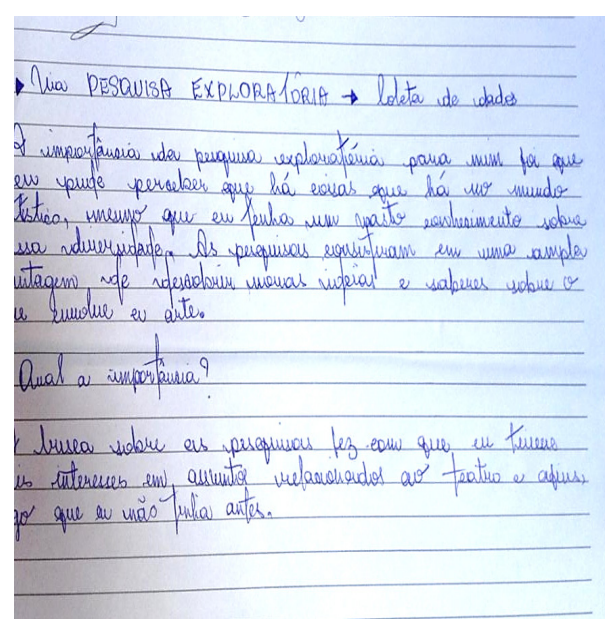

Figura 3. Escritas avaliativas sobre a via Pesquisa Exploratória 


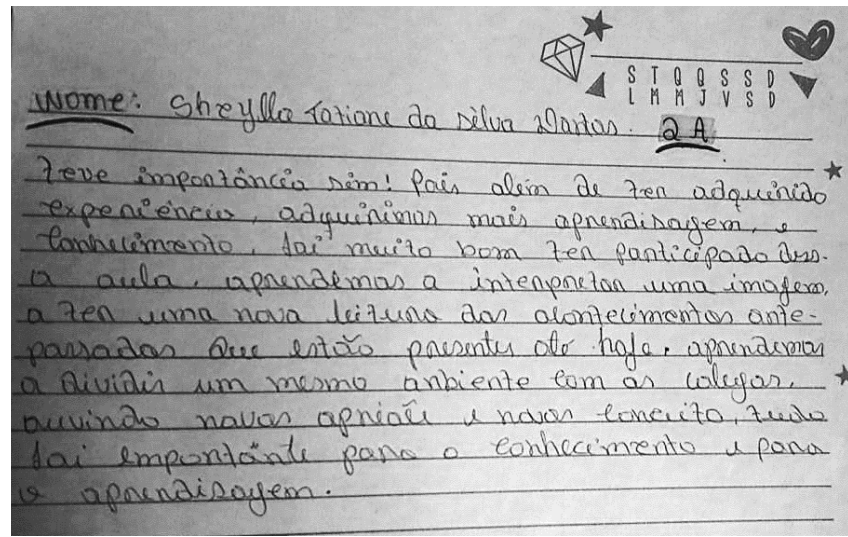

Figura 4. Escritas avaliativas sobre a via Pesquisa Exploratória

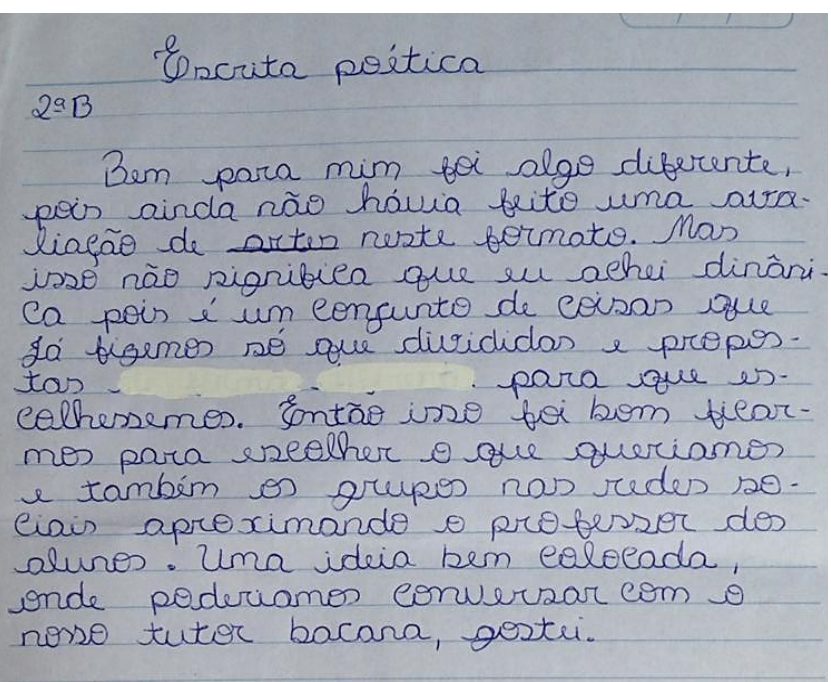

Figura 5. Escrita Poética

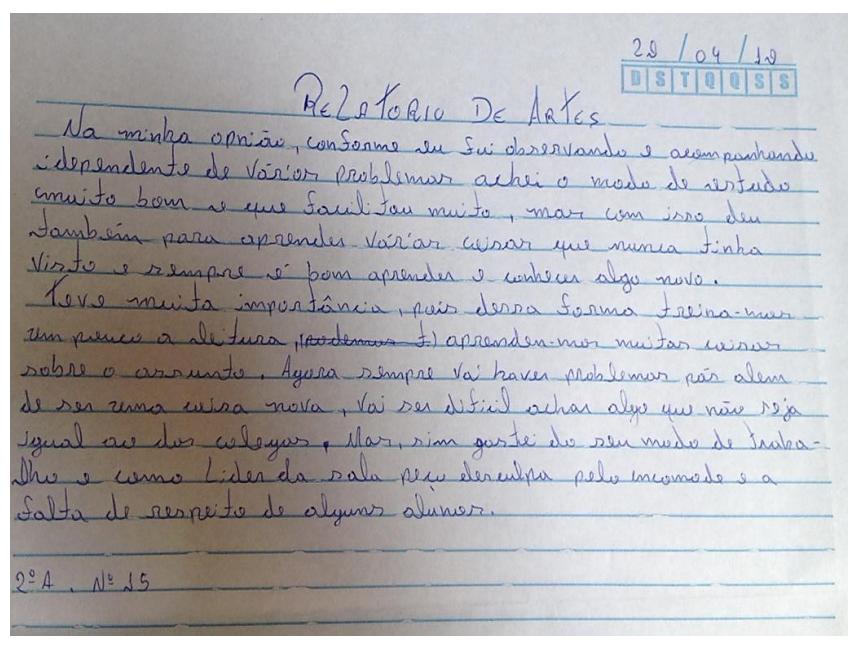

Figura 6. Escritas avaliativas sobre a via Pesquisa Exploratória

\section{Percepções Avaliativas}

Pontos fracos detectados por mim durante a avaliação e escritos coletados: o grupo, às vezes, foi bombardeado de pesquisas iguais uns dos outros, o que transparece um não conferimento por elas/ele. A tentativa de criar um grupo virtual foi pautada na construção e interação com ele, proporcionando coleta, compartilhamento e banco de dados, onde as/os estudantes poderiam ser acessadas com facilidades uns pelos outros. Porém, devido ao grande fluxo das pesquisas foi possível perceber, certa preguiça quanto a conferição.

Houve alguns desconfortos na minha conferição que indicava e sugeria outro tipo de pesquisa quando ela se repetia. Reservei um longe período para conferir todas as pesquisas e considerar a equivalência dos pontos. Muitas/ muitos estudantes ficaram insatisfeitos com a diminuição de sua nota, porém, a vantagem da plataforma é sem dúvidas o registro e a hora, então não tem como justificarem uma negligência.

No caso da via Escrita Poética - notei que o que ficou precária foi mais exemplo, na tentativa de exemplificar apresentei para alguns, cordéis e livros de quadrinhos quando visitamos a biblioteca da escola, dando possibilidades para além da escrita, para uma escrita também visual. $O$ trabalho não exclui alguns textos potentes e instigantes que surgiram de alguns, inclusive, os indiquei para que inscrevessem na “Olimpíada de Língua Portuguesa” - edição 2019.

Noto também que alguns entenderam muito bem os temas tradados nas aulas, desenvolvendo uma escrita também crítica. Percebi que o exercício contribuiu para se pensar em outro tipo de texto argumentativo para além da elaboração de uma redação.

Alguns apenas desenharam as figuras do livro e escreveram apenas palavras, percebo uma certa resistência ao exercício e notei, não um mal entendimento, mas sim uma má vontade de cumpri-lo. Há momentos que podemos avançar e instigar outras proporções metodológicas diferenciadas, mas há outros que precisamos aceitar o próprio desenvolvimento do contexto, revendo na medida do possível nossa prática para desenvolver estratégias que potencializem o ensinoaprendizagem daquele contexto.

Outra grande surpresa para mim foi descobrir que tive uma aluna diagnosticada com retardo mental, graças ao esclarecimento da preceptora, notamos que ela teve dificuldades de realização dos exercícios, porém, uma coisa que percebi foi que quando apresentei um livro em quadrinhos a ela como exemplo para a construção da escrita 
poética, ela conseguiu desenvolver sua escrita poética de modo visual com imagens. Deste modo, considerei sua avaliação divergente do resto da turma. A partir dos textos compartilhados na avaliação (já evidenciados no tópico anterior) do primeiro bimestre, novas vias foram propostas a partir da coleta das escritas e conversas, destaco as novas vias para a nota do segundo bimestre:

\section{OBRA POÉTICA A PARTIR DE FORMAS}

- que podem ser colagens, marionetes, releituras de outras obras dos temas dos livros. (5 obras);

VÍDEO PERFORMERS - criação de vídeos-performers até $60 \mathrm{seg}$ para serem enviados no grupo do WhatsApp ou E-mail. (5 vídeos);

CENA PERFORMATIVA - criação de cena individual ou coletiva, com fala ou sem fala. (máximo 5 minutos)

Trabalho de recuperação: Escrita Poética sobre qualquer tema tratado na aula ou pesquisas próprias.

Verifiquei que no segundo bimestre com o fluxo de entendimento sobre as vias anteriores, o processo se desenvolveu com maior facilidade. Muitas/os estudantes criaram suas obras independentes provocando e incentivando construções seletivas autônomas. Sem que houvesse uma escolha acerca das outras vias, a avaliação sobre elas dificulta o raciocínio reflexivo de desenvolvimento. Os materiais elaborados geraram diversas obras

com a colagem que foram expostas na parede da própria sala de aula, igualmente como no primeiro semestre, foi proposto uma abertura para uma escrita a qual elas e eles puderam me dá um retorno que serviu para refletir sobre a metodologia lançada. Destaco a seguir algumas delas.

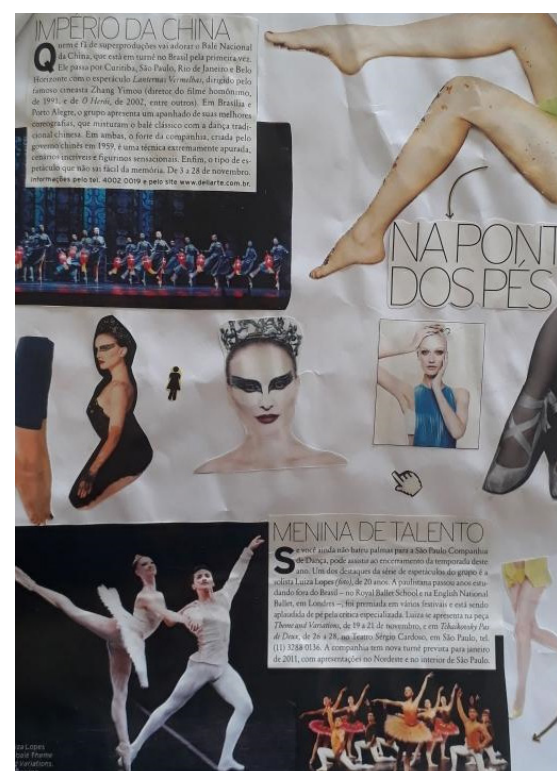

Figura 7. Obra poética realizada a partir de formas utilizando colagem

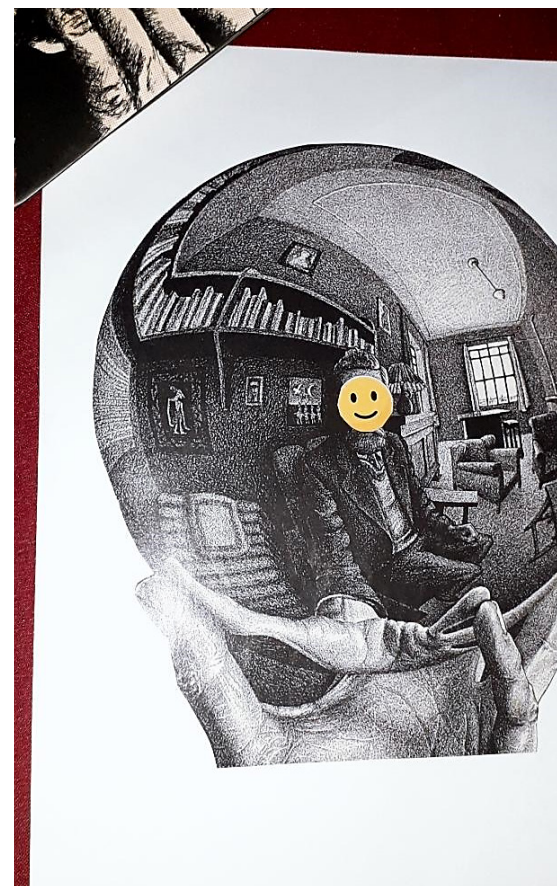

Figura 9. Obra poética realizada a partir de formas utilizando colagem

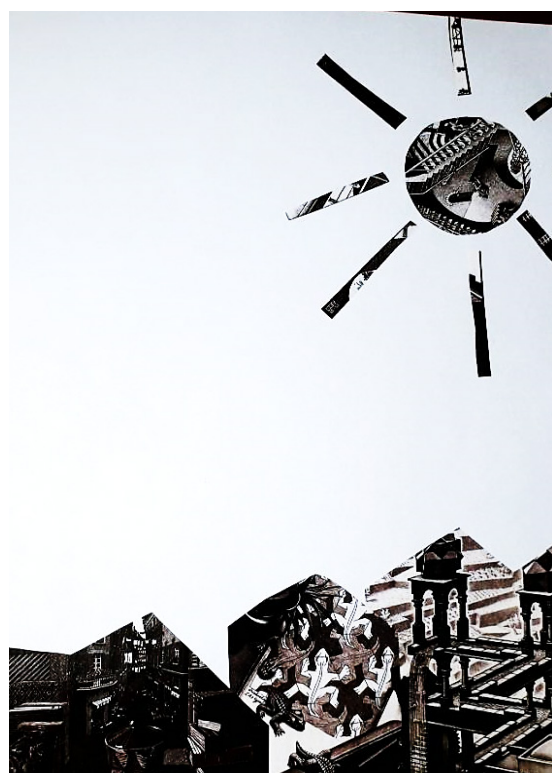

Figura 8. Obra poética realizada a partir de formas utilizando colagem

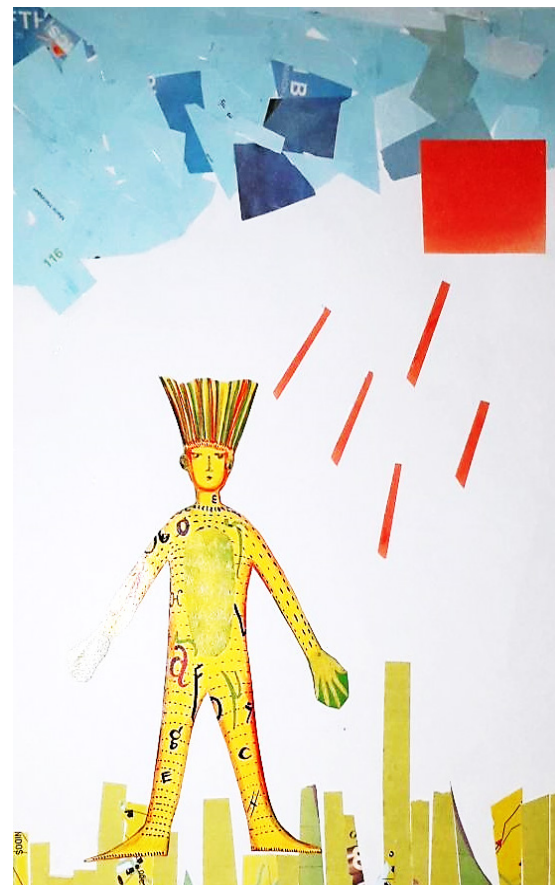

Figura 10. Obra poética realizada a partir de formas utilizando colagem 


\section{Considerações Finais}

Não foquei a um campo de montagem cênica, também pelas observações que fui tendo ao longo do processo de imersão e dos estágios supervisionados da própria graduação em Licenciatura em Teatro da URCA, deste modo, preferi uma busca por outras estratégias para que possibilitasse um campo artístico com outros aspectos como: elaborações de escritas poéticas, obras poéticas (colagens, videoperformances, dentre outros), sempre em diálogo com o conteúdo programado do livro. Na residência dei importância a esse suporte assim como valorização.

Sobre o bloco da imersão a contribuição que podemos destacar é a temporalidade para conhecer, observar e pensar em estratégias que podem ser percebidas em um primeiro momento com a turma, bem como, conhecer suas estruturas e políticas, principalmente pelo apoio e sugestão da professora formada em teatro, seu diálogo, compartilhamento, sugestão e estar à frente de uma responsabilidade maior, proporcionou um acentualmente ético e profissional por levar o programa a sério e potente para a investigação metodológica desenvolvida com mais precisão e tempo.

O projeto em si é relevante na medida em que podemos propor e aprofundar metodologias e associá-las concomitantemente com os conteúdos do livro. Ao vivenciar a escola por um período maior, foi possível entender melhor sua estruturação sociopolítica. Porém, o projeto deixa a desejar em alguns aspectos que destaco abaixo:

Ele não viabilizou e reconheceu a realidade da matéria Artes (ou outras que tem poucas aulas por semana), pois não atentou para sua carga horária e poucas professoras e professores formadas/formados e que são efetivos na área. Ao propor que a preceptora esteja com o residente, isso impediu de reconhecer outras práticas, sobretudo de outras profissionais que atuam na disciplina, levando em consideração sua resolução polivalente. O que atrapalhou e saturou uma busca pelo preenchimento de carga horária exigida durante todos os blocos do projeto.
A arte tem suas especificidades artísticas-teóricas diferenciadas das demais, pois engloba uma série de estruturação e materiais que são precários para o desenvolvimento de algumas atividades, no caso teatral, tais como: espaço vazio e limpo para as atividades de cunho corporal-prático. Não consegui realizar nenhuma atividade corporal, mas também não foi meu foco, busquei outras metodologias que foram evidenciadas até aqui, com a pretensão de provocar um outro lugar de ensinoaprendizagem levando em consideração o contexto precário em que podemos nos encontrar.

O projeto não deixou claro a especificidade dessa forma do preenchimento de carga horária do bloco da "regência", transparecendo e reforçando ainda mais o sucateamento desta linguagem. Diante disso, estratégias foram repensadas para dar conta da carga total exigida, como mediações, acompanhamento de processos artísticas e proposições de minicursos que reforçam a prática didático-pedagógica do residente-pesquisador. As estratégias propostas com as vias possibilitaram uma construção de grupalidade interessante com as escolhas de forma horizontal pelas pesquisas próprias, evidencia-se também, uma abordagem que utilizou da autonomia, elaboração de escrita e assimilação dos conteúdos.

\section{Referências}

ALMEIDA, Neide A... [ET al]. (2013) Linguagens e Códigos: ensino médio: educação de jovens e adultos. (1th. ed). São Paulo: Global.

MEIRA, Beá. (2010). Percursos da arte: volume único: ensino médio: arte. (1th.ed). São Paulo: Scipione.

PILETTI, N., \& ROSSATO, S. M. (2010). PSICOLOGIA DA APRENDIZAGEM: da teoria do Condicionamento ao Construtivismo. São Paulo: CONTEXTO. 